Article

\title{
Optimization of Laser Powder Bed Fusion Processing Using a Combination of Melt Pool Modeling and Design of Experiment Approaches: Density Control
}

\author{
Morgan Letenneur, Alena Kreitcberg and Vladimir Brailovski * \\ Department of Mechanical Engineering, École de technologie supérieure, 1100 Notre-Dame Street West, \\ Montreal, QC H3C 1K3, Canada; morgan.letenneur.1@etsmtl.net (M.L.); alena.kreitcberg.1@ens.etsmtl.ca (A.K.) \\ * Correspondence: vladimir.brailovski@etsmtl.ca; Tel.: +1-514-396-8594
}

Received: 18 December 2018; Accepted: 12 February 2019; Published: 21 February 2019

\begin{abstract}
A simplified analytical model of the laser powder bed fusion (LPBF) process was used to develop a novel density prediction approach that can be adapted for any given powder feedstock and LPBF system. First, calibration coupons were built using IN625, Ti64 and Fe powders and a specific LPBF system. These coupons were manufactured using the predetermined ranges of laser power, scanning speed, hatching space, and layer thickness, and their densities were measured using conventional material characterization techniques. Next, a simplified melt pool model was used to calculate the melt pool dimensions for the selected sets of printing parameters. Both sets of data were then combined to predict the density of printed parts. This approach was additionally validated using the literature data on AlSi10Mg and 316L alloys, thus demonstrating that it can reliably be used to optimize the laser powder bed metal fusion process.
\end{abstract}

Keywords: additive manufacturing; laser powder bed fusion; process optimization; analytical model

\section{Introduction}

Interest in laser powder bed fusion (LPBF) additive manufacturing (AM) has spiked in many industries, creating a high demand for new AM-ready metallic materials [1]. However, the mechanical properties, surface finish, and precision of LPBF parts are dependent on more than 60 processing parameters [2], which all need to be optimized. There are currently two main ways to realize this process optimization for new alloys. Most often, this optimization is carried out by defining an experiment plan that covers different arrangements of laser power, scanning speed, hatching space, layer thickness, scanning strategy and part orientation for a given alloy [3-10]. Once the specimens are printed, their mechanical properties are evaluated and a conclusion is drawn on the influence of the different processing parameters on the final part geometric and service attributes. This approach yields satisfying results, but requires multiple printing jobs and time-consuming post-processing experiments. It could easily be realized for a single alloy, but becomes prohibitively expensive if multiple process optimization campaigns are required.

Another way a new AM material can be introduced is by applying a numerical modeling approach with the objective of finding the appropriate printing parameters, as shown in [11-15]. However, due to a large number of variables, these models require significant time and computer resources to model a single laser track, let alone a complex part. Moreover, the more complex the model, the more laborious the calibration procedure, which makes the process optimization more cumbersome and labor-intensive.

In this work, we investigate the possibility of using a combination of a simplified analytical model of the melt pool and of an experimental calibration routine to create a density control algorithm for the 
laser powder bed fusion process. The main objective of this approach is to reduce the time, the number of printing jobs and the quantity of post-processing characterization work needed to optimize the process for any given powder feedstock and any given LPBF system.

\section{Methodology}

Previous studies have demonstrated that the density of LPBF manufactured parts is mostly dependent on the following three dimensionless melt pool metrics (Figure 1): melt pool depth-to-layer thickness ratio $(D / t)$, melt pool width-to-hatching space ratio $(W / h)$, and melt pool length-to-melt pool width ratio $(L / W)$, and that the highest density is generally obtained for $1.5<D / t<2,1.5<W / h<2.5$ and $L / W<2 \operatorname{Pi}[16,17]$. Based on these observations, we investigated the possibility of using the $D / t$, $W / h$ and $L / W$ ratios to correlate a specific combination of LPBF processing parameters (laser power, scanning speed, layer thickness, and hatching space) with the density of a printed material.

This study was conducted in three phases: first, the analytical model of a thermal field generated by a moving heat source in a solid body is used to evaluate the melt pool dimensions for a given set of LPBF processing parameters. Then, a relationship between the melt pool dimensions and the density of the printed material was found experimentally for a given material and LPBF system. Finally, using the numerical model developed and the experimental relationship found, the LPBF processing parameters were linked to the density of the manufactured parts with the objective of developing a porosity prediction algorithm for different materials and different LPBF systems.

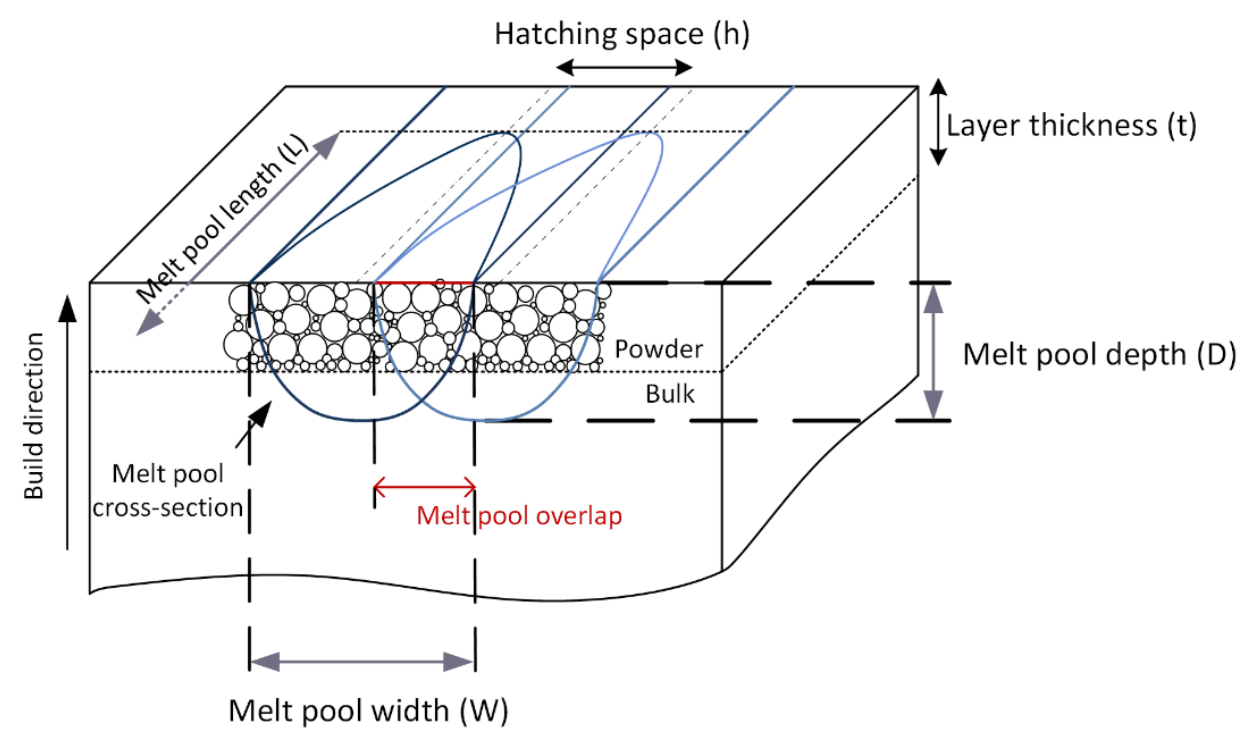

Figure 1. Schematic representation of the melt pool and the corresponding geometric characteristics [18].

\subsection{Melt Pool Calculations}

First, calculations of the LPBF melt pool dimensions were carried out using the analytical model of a semi-infinite solid with a moving Gaussian heat source [19]. This model has been successfully used for the determination of the LPBF processing parameters for pure iron [18] and Ti-Zr-Nb alloy [20]. The Gaussian model involves a symmetrical distribution of laser irradiance across the beam. The energy from the laser is assumed to be applied on the powder bed surface for a time interval defined by the scanning speed and the laser spot size. In this case, for a Gaussian beam moving with a given velocity, the temperature distribution $T(x \cdot y \cdot z)$ in the powder bed is calculated by Equations (1)-(3):

$$
T(x \cdot y \cdot z)=T_{0}+\frac{A P}{k r_{f} \pi^{\frac{3}{2}}} \int_{\infty}^{0} \frac{1}{1+\tau^{2}} \exp (C) d \tau
$$




$$
\begin{gathered}
C=-\frac{\tau^{2}}{1+\tau^{2}}\left[\left(\xi-\frac{P_{e}}{2 \tau^{2}}\right)^{2}+\eta^{2}\right]-\tau^{2} \zeta^{2} \\
\xi=\sqrt{2} \frac{x}{r_{f}} \cdot \eta=\sqrt{2} \frac{y}{r_{f}} \cdot \zeta=\sqrt{2} \frac{z}{r_{f}} \cdot P e=\frac{r_{f} \mathrm{~V}}{2 \sqrt{2} \alpha} \cdot \tau=\frac{r_{f}}{2 \sqrt{2 \alpha t}}
\end{gathered}
$$

where $T_{0}$ is the powder bed temperature $\left({ }^{\circ} \mathrm{C}\right) ; A$, the absorptivity; $P$, the laser power $(\mathrm{W}) ; k$, the thermal conductivity $(\mathrm{W} /(\mathrm{m} \cdot \mathrm{K})) ; r_{f}$, the laser beam radius $(\mathrm{m}) ; P e$, the Peclet number; $v$, the scanning speed $(\mathrm{m} / \mathrm{s}) ; \alpha$, the thermal diffusivity $\left(\mathrm{m}^{2} / \mathrm{s}\right) ; \rho$, the material density $\left(\mathrm{kg} / \mathrm{m}^{3}\right) ; c_{p}$, the specific heat $(\mathrm{J} /(\mathrm{kg} \cdot \mathrm{K}))$, and $t$, time (s).

The laser energy absorptivity $A$ is estimated using Equation (4) from the Drude's theory [19,21]:

$$
A \approx 0.365\left(\lambda \sigma_{0}\right)^{-0.5}=0.365\left(\frac{\rho_{0}}{\lambda}\right)^{0.5}
$$

where $\lambda$ is the laser wavelength $(\mu \mathrm{m}), \sigma_{0}$, the electrical conductivity $(\mathrm{S} / \mathrm{m})$, and $\rho_{0}$, the electrical resistivity of the irradiated material $(\mathrm{Ohm} \cdot \mathrm{m})$.

\subsection{Experimental Calibration}

\subsubsection{Materials, Equipment and Plan of Experiment}

The experimental part of this study was conducted using the EOS-supplied IN625 powder and an EOSINT M280 LPBF system (EOS GmbH, Munich, Germany) equipped with a $400 \mathrm{~W}$ ytterbium fiber laser (beam radius $r_{f}=50 \mu \mathrm{m}$ ). The initial temperature of the substrate (build platform) $T_{0}=60^{\circ} \mathrm{C}$. To design the plan of experiments, the analytical model represented by Equations (1)-(4) was used first. To this end, the following physical properties of an irradiated body: thermal conductivity $k_{0}$ [22], specific heat $C_{p 0}$ [23], and electrical resistivity $\rho_{0}$ [24] need to be calculated, taking into account the effective powder bed density $\varphi$, the latter being the powder morphology and spreading mechanism-dependent:

$$
k=k_{0} \times \frac{\varphi}{0.5(3-\varphi)} ; C_{p}=C_{p 0} \times \varphi ; \rho=0.696 \times \frac{4}{\varphi} \times \rho_{0}
$$

In this work, the density $\phi$ of IN625 powder spread by a standard EOS metal doctor blade and measured using the encapsulated samples method [25] was found to be close to $60 \%$. Given the preceding, the IN625 alloy properties used for calculations are shown in Table 1 . They were taken at room temperature, and it is considered that the preceding layer cools down to $60^{\circ} \mathrm{C}$ between two scanning runs.

Table 1. Physical properties of IN625 powder [26,27].

\begin{tabular}{ccc}
\hline & Bulk & Powder $(\boldsymbol{\varphi}=\mathbf{6 0} \mathbf{0})$ \\
\hline Melting temperature, ${ }^{\circ} \mathrm{C}$ & 1350 & 1350 \\
Density, $\mathrm{kg} / \mathrm{m}^{3}$ & 8440 & 5072 \\
Thermal conductivity, $\mathrm{W} /(\mathrm{m} \cdot \mathrm{K})$ & 25.2 & 15.1 \\
Specific heat capacity, $\mathrm{J} / \mathrm{kg} \cdot \mathrm{K})$ & 670 & 403 \\
Electrical resistivity, $10^{-8} \Omega \cdot \mathrm{m}$ & 134 & 223 \\
\hline
\end{tabular}

The temperature distribution map shown in Figure 2 represents an example of calculations using Equations (1)-(5). It corresponds to the following set of LPBF processing parameters: $P=270 \mathrm{~W}$, $v=1000 \mathrm{~mm} / \mathrm{s}$, and $t=40 \mu \mathrm{m}$ applied to IN625 powder (Table 1). From this temperature map, the melt pool width, depth and length are delimited by the alloy melting temperature of $1350{ }^{\circ} \mathrm{C}: W=173 \mu \mathrm{m}$, $D=89 \mu \mathrm{m}$, and $L=806 \mu \mathrm{m}$, which correspond to the following dimensionless metrics: $D / t=2.2$ and 
$L / W=4.7$ (since only a single track is modeled, the hatching space $h$ is not considered at this stage). This calculation procedure can be repeated for any material and any given set of processing parameters.

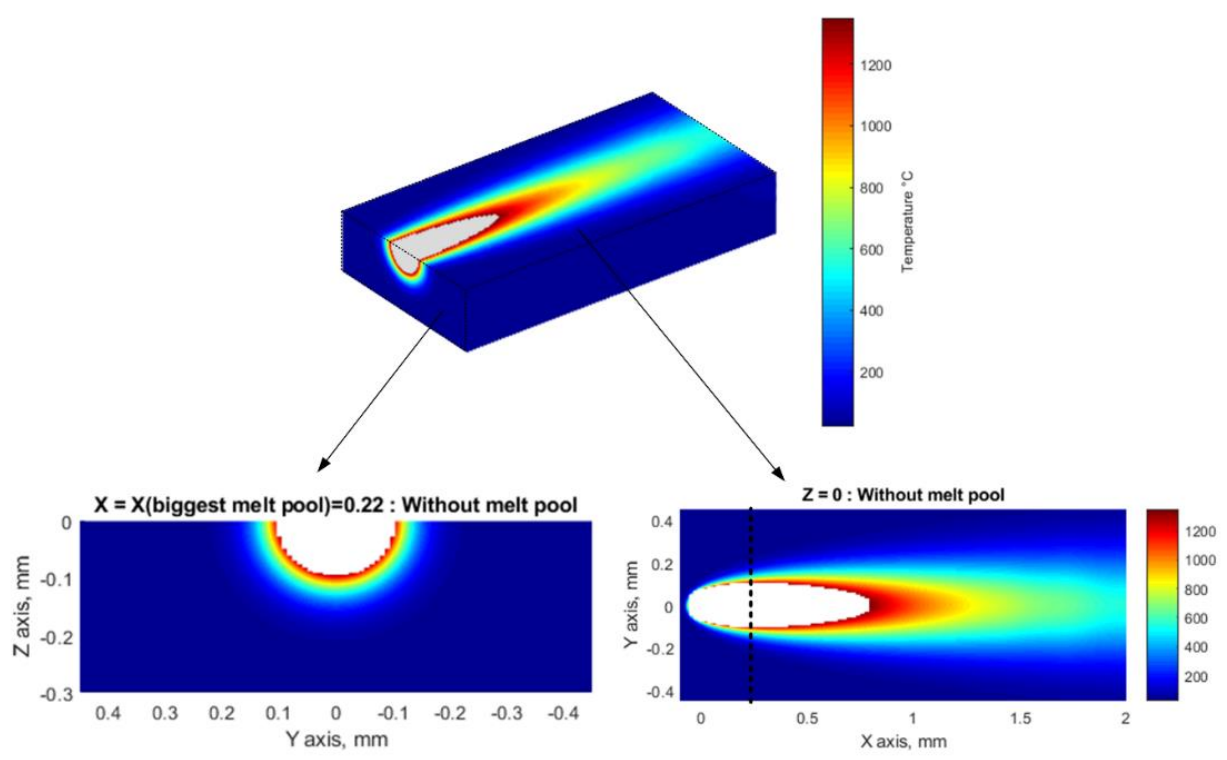

Figure 2. Melt pool dimensions for IN625 powder when $P=270 \mathrm{~W}, v=1000 \mathrm{~mm} / \mathrm{s}$, and $t=40 \mu \mathrm{m}$; the melt pool width and depth are delimited by the alloy melting temperature.

\subsubsection{Melt Pool Dimensions-Density Relationship}

To establish the relationship between the previously defined dimensionless melt pool metrics and the density of manufactured parts, $10 \mathrm{~mm}$-diameter $15 \mathrm{~mm}$-height cylindrical coupons of IN625 alloy were printed to cover a $D / t$ ratio ranging from 1 to $3.5, W / h$, from 0.5 to 3 and $L / W$, from 3 to 6 . To find the LPBF parameters resulting in these melt pool dimensions, the following ranges of printing parameters were reversely computed using the melt pool model presented in Section 2.1: the laser power varying from 160 to $350 \mathrm{~W}$, the scanning speed, from 560 to $2800 \mathrm{~mm} / \mathrm{s}$, and the hatching space, from 30 to $550 \mu \mathrm{m}$; the layer thickness $\mathrm{t}$ was kept constant at $40 \mu \mathrm{m}$ (see Table 2 for the selected values of the LPBF processing parameters). Two specimens were printed for each set of printing parameters.

Table 2. Imposed melt pool metrics and calculated processing parameters (plan of experiments).

\begin{tabular}{ccc}
\hline & & Melt Pool Dimensionless Metrics \\
\hline \multirow{3}{*}{ Imposed } & $D / t$ & $1,1.5,2,2.5,3,3.5$ \\
& $W / h$ & $0.5,1,1.5,2,2.5,3$ \\
& $L / W$ & $3.2,3.9,4.5,5$ \\
\hline & & LPBF Processing Parameters \\
\hline \multirow{3}{*}{ Calculated } & Laser power $P, \mathrm{~W}$ & $160,225,340,345,350$ \\
& Scanning speed $v, \mathrm{~mm} / \mathrm{s}$ & $560,800,1060,1180,1680,1940,2800$ \\
& Layer thickness $t, \mu \mathrm{m}$ & 40 \\
& Hatching space $h, \mu \mathrm{m}$ & $30,40, \ldots, 180,190,210,230,270,280,350,390,430,470,550$ \\
\hline
\end{tabular}

After processing, the printed coupons were cut off the build plate and their densities measured using the Archimedes' technique (ASTM B962-15). Each density measurement using a SARTORIUS Secura 324-1s scale (Sartorius, Goettingen, Germany), having a precision of $\sim 0.001 \mathrm{~g}$, was repeated at least 3 times.

The results of this experiment are collected in Table 3 (Appendix A) and plotted in Figure 3 in the $D / t-W / h$-density coordinates. It can be seen from this figure that the density of IN625 coupons exceeding $99.5 \%$ (this value was selected arbitrarily to limit the amount of experimental data, while leaving enough space for optimization) was obtained for a $D / t$ ratio ranging from 1.5 to 2.75 and a $W / h$ 
ratio ranging from 1.8 to 2.8. The corresponding $L / W$ ratio ranged from 3.8 to 4.6 (not shown on this diagram). Note that the calculated values fall close to the ranges recommended in the literature, which are $1.5<D / t<2,1.5<W / h<2.5$ and $L / W<2 \mathrm{Pi}[28]$.

From Figure 3 , assuming that the calculated $D / t, W / h$ ratios correspond to the effectively obtained melt pool dimensions, the materials density can be expressed as their function as follows:

$$
\rho=a 0+a 1 \cdot\left(\frac{D}{t}\right)+a 2 \cdot\left(\frac{W}{h}\right)+a 3 \cdot\left(\frac{D}{t}\right)^{2}+a 4 \cdot\left(\frac{D}{t}\right) \cdot\left(\frac{W}{h}\right)+a 5 \cdot\left(\frac{W}{h}\right)^{2}
$$

where $a 0=0.512, a 1=0.212, a 2=0.225, a 3=-0.027, a 4=-0.384$, and $a 5=-0.031$.

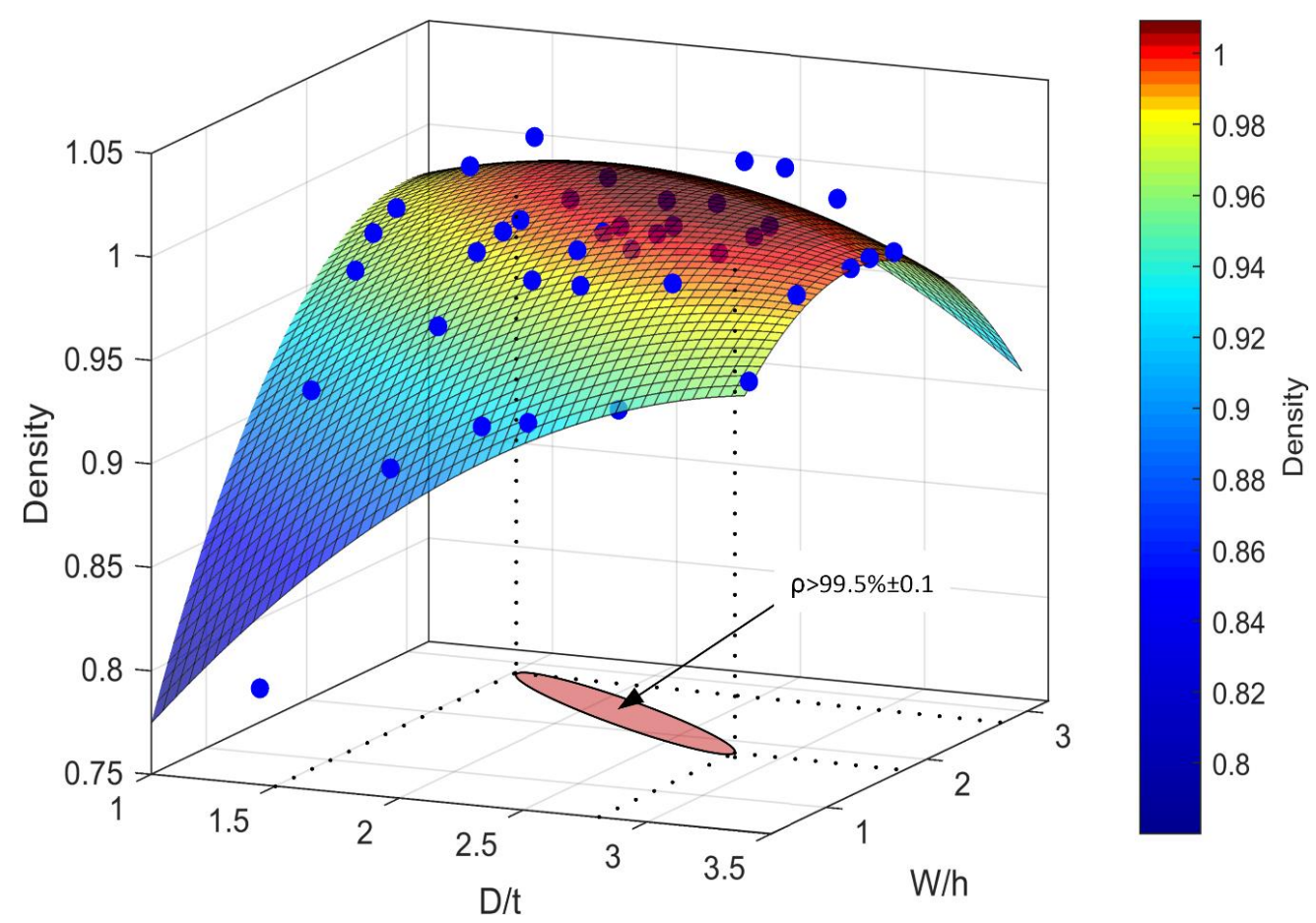

Figure 3. Density of the printed coupons as a function of the $D / t$ and $W / h$ ratios; the calculated $D / t-W / h$ area corresponds to the measured density of the printed material exceeding $99.5 \pm 0.1 \%$.

\subsection{Energy Density-Build Rate Processing Map}

In this work, the LPBF processing conditions were expressed by a combination of two metrics: the volumetric laser energy density $E\left(\mathrm{~J} / \mathrm{mm}^{3}\right)(7)$ and the material build rate $B R\left(\mathrm{~cm}^{3} / \mathrm{h}\right)(8)$; the product of both corresponds to the laser power $P$ (Watts).

$$
\begin{aligned}
& E\left(J / \mathrm{mm}^{3}\right)=\frac{P}{v \cdot h \cdot t} \\
& B R\left(\mathrm{~cm}^{3} / h\right)=v \cdot h \cdot t
\end{aligned}
$$

Next, the analytical model (1-5) and Table 1 were used to map three $E-B R$ areas corresponding to the experimentally obtained optimal ranges of the melt pool metrics (Figure 4a): $D / t=1.5-2.75$, $W / h=1.8-2.8$, and $L / W=3.8-4.6$. These maps are calculated by varying the laser power from 20 to $380 \mathrm{~W}$; the scanning speed, from 100 to $4000 \mathrm{~mm} / \mathrm{s}$; the hatching space, from 30 to $200 \mu \mathrm{m}$, and the layer thickness, from 20 to $80 \mu \mathrm{m}$.

Three $E-B R$ areas of Figure $4 a$ were then superposed in Figure $4 \mathrm{~b}$ to schematically delimit a common processing window, which must guarantee the maximum density of printed IN625 parts. Next, the densities of the printed coupons (Figure 3 and Table 1 in the Annex) were superposed on this 
processing window, and it can be seen that the coupons with a density $\geq 99.5 \%$ are indeed located, within a certain margin of error, in the numerically predicted optimal processing window. By refining the scanning steps and using calibration Equation (6), the described approach can then be used to build a more detailed processing map for IN625 powder (Figure 4c).

(a)

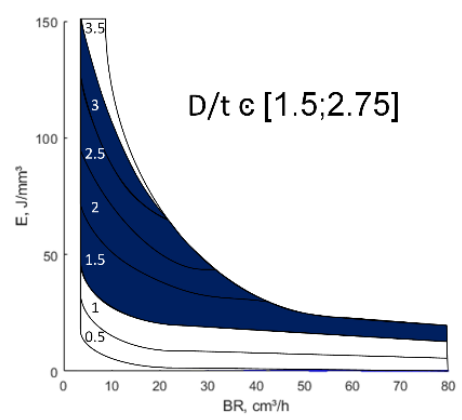

(b)

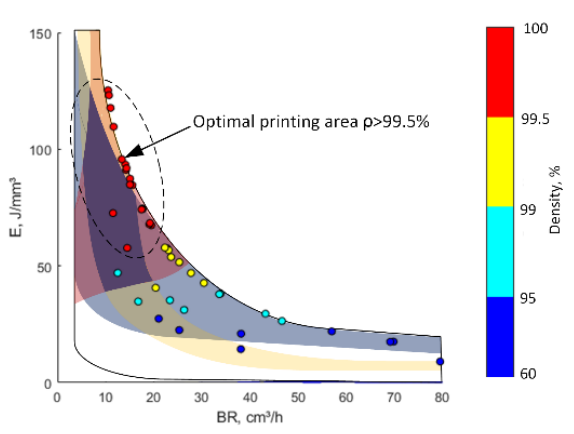

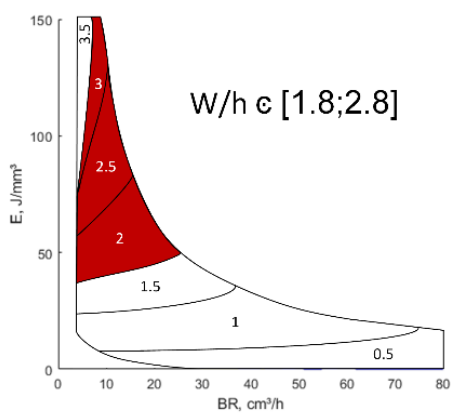

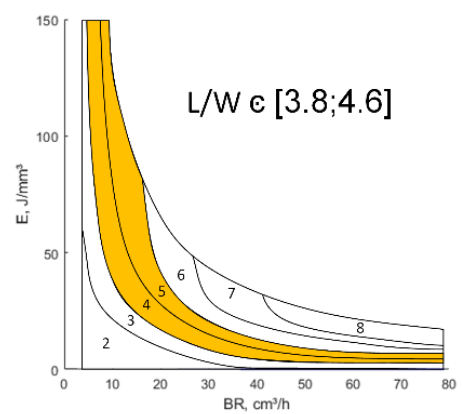

(c)

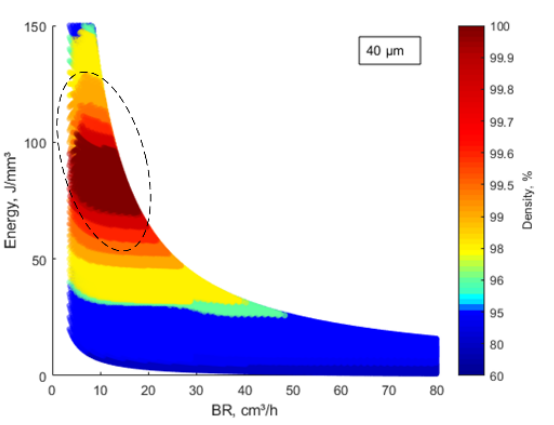

Figure 4. (a) Optimal areas for the $D / t, W / h$, and $L / W$ ratios; (b) superposition of the numerically optimized processing window; (c) experimentally calibrated processing map.

\subsection{Validation Strategy for the Proposed Processing Optimization Approach}

We hypothesize that such a combined processing optimization approach is valid for any material processed by a given LPBF system. In our case it is the EOS M280 LPBF system. To verify this hypothesis, the results of such an optimization were compared with the numerical and experimental data found in the literature. This comparison was carried out in two phases: first, the melt pool dimensions were calculated for AlSi10Mg and 316L powders using a simplified analytical model of this work (Equations (1)-(5)), and then compared against those obtained for the same feedstock material, but using more powerful finite element models (FEM). These FEM models take into account the optical penetration depth, the mass transfer-related phenomena, such as the Marangoni convection and the Rayleigh capillary flow, and the heat losses to the environment [11,29]. Secondly, the numerically predicted densities for pure iron and Ti-6Al-4V alloy powders are compared with their experimentally measured equivalents from [6] and [18]. The optimal processing windows for all these validation studies were obtained using the algorithm previously presented. The data used for these calculations were taken from the corresponding literature sources.

\section{Validation}

\subsection{Melt Pool Dimensions (Single Track)}

As experimental validation of the melt pool model used in this study (Equations (1)-(5)) has already been carried out in our previous work [20], a decision was made to extend the validation experiments to literature data. With this objective in mind, the single track melt pool dimensions calculated by the said analytical model were compared with those calculated by two different finite 
element models. Note that each of these models was experimentally validated by their authors for two different alloys: 316L [11] and AlSi10Mg [14]. For ease of understanding and because the width and the depth of the melt pool are the most important characteristics impacting the density of the printed material, the geometric validation was limited to these two characteristics.

Regarding 316L, the simulations were carried out with an initial powder bed temperature of $296 \mathrm{~K}$ (first track in [11]), a fixed laser power of $110 \mathrm{~W}$ and a scanning speed ranging from 80 to $150 \mathrm{~mm} / \mathrm{s}$. For AlSi10Mg, the simulations were realized for a laser power ranging from 150 to $300 \mathrm{~W}$ and a fixed scanning speed of $200 \mathrm{~mm} / \mathrm{s}$ [14]. In both cases, computations using (Equations (1)-(5)) were carried out using the physical properties taken from the corresponding literature sources (Table 3). In other words, the electrical resistivity, the thermal conductivity and the specific heat capacity values used in our calculations were set identical to those used in [11] and [14] and recalculated for a $60 \%$ powder bed density. This last value was selected on the basis of our previous results because no such information was provided in the literature sources.

Table 3. Physical properties of the AlSi10Mg [13] and 316L [15] powders used for melt pool modeling.

\begin{tabular}{ccccc}
\hline & \multicolumn{2}{c}{ AlSi10Mg } & \multicolumn{2}{c}{ 316L } \\
\cline { 2 - 5 } & Bulk & Powder $(\boldsymbol{\varphi = 6 0} \%)$ & Bulk & Powder $(\boldsymbol{\varphi}=\mathbf{6 0} \mathbf{0})$ \\
\hline Melting temperature, ${ }^{\circ} \mathrm{C}$ & 600 & 600 & 1400 & 1400 \\
Density, $\mathrm{kg} / \mathrm{m}^{3}$ & 2650 & 1590 & 8000 & 4800 \\
Thermal conductivity, $\mathrm{W} /(\mathrm{m} \cdot \mathrm{K})$ & 147 & 88.2 & 16.2 & 9.7 \\
Specific heat capacity, $\mathrm{J} /(\mathrm{kg} \cdot \mathrm{K})$ & 739 & 443.4 & 530 & 318 \\
Electrical resistivity, $10^{-8} \Omega \cdot \mathrm{m}$ & $7.8[30]$ & 4.7 & 74 & 123 \\
\hline
\end{tabular}

The melt pool profiles calculated by the model of this study and those found in the literature are plotted in Figure 5 for different sets of printing parameters. The mean deviations between the results of the analytical and the finite element models are $4.3 \pm 1.2 \%$ for $316 \mathrm{~L}$ and $10.5 \pm 5.8 \%$ for AlSi10Mg. (Note that the numerically estimated impact of a 5.8\% deviation in the AlSi10Mg melt pool dimensions would have introduced only $\sim 0.2 \%$ variation in the predicted density values; the last number being calculated by introducing a value of $5.8 \%$ in the density Equation (6)).

(a)

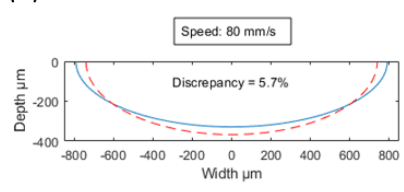

(b)

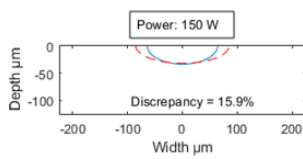

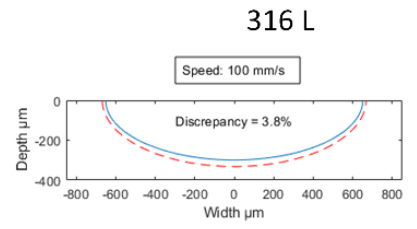

AlSi10Mg
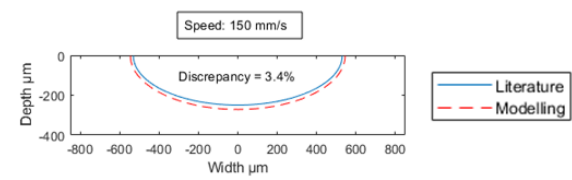

Figure 5. Comparison of the melt pools profiles for (a) 316L [11] and (b) AlSi10Mg [14] alloys.

\subsection{Density of the Same Alloy Printed with Two Different Layer Thicknesses}

Using a combination of the analytical modeling of melt pool dimensions (Equations (1)-(5)) and Equation (6), representing the correspondence between the melt pool dimensions and the density of the printed parts, processing windows can be calculated for multi-track LPBF. To validate this approach, processing maps for Ti64 alloy printed with two layer thicknesses (30 and $60 \mathrm{um}$ ) are plotted in Figure 6. The physical properties used for these calculations are collected in Table 4.

Note that the powder bed densities (evaluated using the method of encapsulated samples [25]) in these two cases are not identical: it is higher in the former than in the latter case, with $\varphi=70 \%$ for $t=30 \mu \mathrm{m}$ and $\varphi=60 \%$ for $t=60 \mu \mathrm{m}$. These changes in the powder bed density are due to the 
differences in the powder spreading conditions for different layer thicknesses as demonstrated in [31]. If a layer thickness is smaller than the D90 value of the powder particle distribution [32], the density increases because the biggest particles are kept at the top of the layer and finally swept out by the recoater [33], which increases the powder bed density. It can be seen from Figure 6 that the higher the powder bed density ( $70 \%$, Figure $6 \mathrm{~b}$, instead of $60 \%$, Figure $6 a)$, the higher the optimal laser power density, while the lower the build rate of the process. Similar results were reported in [31].

(a)

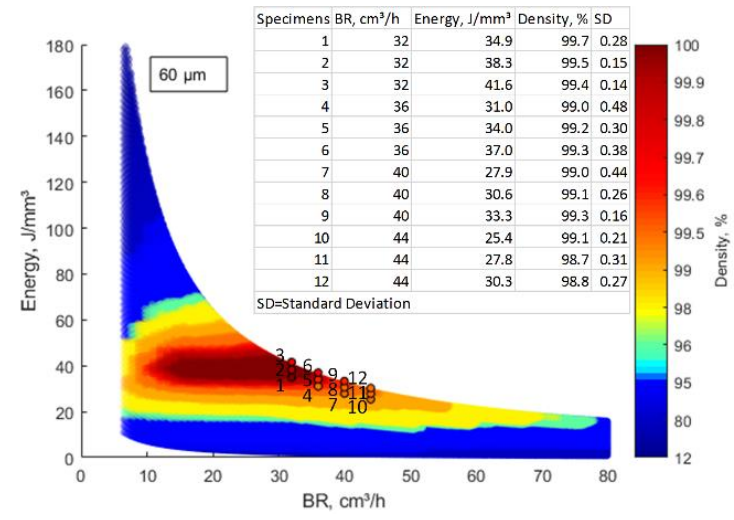

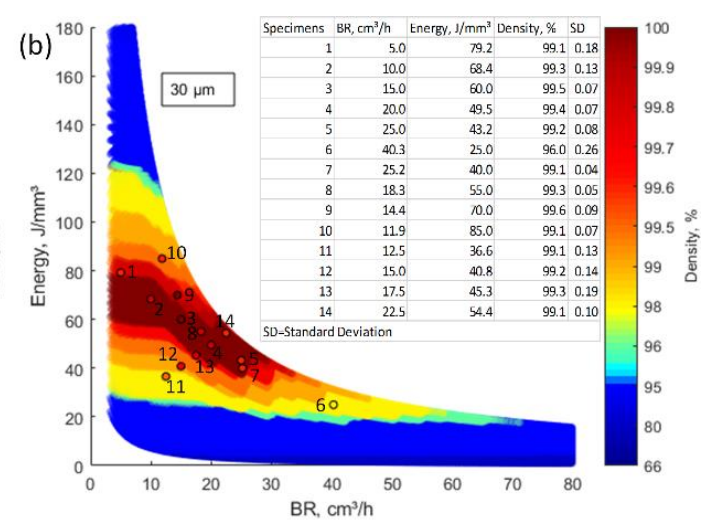

Figure 6. Processing maps for Ti64 alloy for layer thicknesses of (a) $60 \mu \mathrm{m}$ and (b) $30 \mu \mathrm{m}$ (EOS M 280).

Table 4. Physical properties of Ti64 powders used for melt pool modeling [26,34].

\begin{tabular}{cccc}
\hline & \multicolumn{2}{c}{ Ti64 $(t=\mathbf{6 0} \boldsymbol{\mu m})$} & Ti64 $(t=\mathbf{3 0} \boldsymbol{\mu m})$ \\
\cline { 2 - 4 } & Bulk & Powder $(\boldsymbol{\varphi}=\mathbf{6 0} \%)$ & Powder $(\boldsymbol{\varphi}=\mathbf{7 0} \%)$ \\
\hline Melting temperature, ${ }^{\circ} \mathrm{C}$ & 1660 & 1660 & 1660 \\
Density, $\mathrm{kg} / \mathrm{m}^{3}$ & 4410 & 2630 & 3150 \\
Thermal conductivity, $\mathrm{W} /(\mathrm{m} \cdot \mathrm{K})$ & 7.3 & 4.27 & 5.18 \\
Specific heat capacity, $\mathrm{J} /(\mathrm{kg} \cdot \mathrm{K})$ & 570 & 342 & 405 \\
Electrical resistivity, $10^{-8} \Omega \cdot \mathrm{m}$ & 170 & 283 & 239 \\
\hline
\end{tabular}

The experimentally measured densities of Ti64 coupons printed with the layer thicknesses of $t=60 \mu \mathrm{m}$ (Figure 6a) and $30 \mu \mathrm{m}$ (Figure 6b) were then superposed on the calculated processing maps (these coupons were printed using EOS Ti64 powder and the EOS M280 system of this study). The mean porosity deviations for $t=60 \mu \mathrm{m}$ corresponded to $0.8 \%$, while for $t=30 \mu \mathrm{m}$, it was $0.4 \%$.

\subsection{Density of Two Different Alloys}

The reliability of the proposed processing optimization approach was then studied for Fe [18] and AlSi10Mg [35] powders. The density predictions were made using the physical properties of Table 5 and the processing maps are plotted in Figure $7 \mathrm{a}, \mathrm{b}$. The experimentally measured density values were superposed, and the deviations between the model and the experiment corresponded to $0.8 \%$ for $\mathrm{Fe}$ and $0.7 \%$ for AlSi10Mg powders.

Table 5. Physical properties of Fe [3] and AlSi10Mg [20] powders used for melt pool modeling.

\begin{tabular}{|c|c|c|c|c|}
\hline & \multicolumn{2}{|r|}{ Fe } & \multicolumn{2}{|r|}{ AlSi10Mg } \\
\hline & Bulk & $\begin{array}{c}\text { Powder }(t=60 \mu \mathrm{m} ; \\
\varphi=60 \%)\end{array}$ & Bulk & $\begin{array}{c}\text { Powder }(t=30 \mu \mathrm{m} ; \\
\varphi=45 \%)\end{array}$ \\
\hline Melting temperature, ${ }^{\circ} \mathrm{C}$ & 1660 & 1660 & 600 & 600 \\
\hline Density, $\mathrm{kg} / \mathrm{m}^{3}$ & 8000 & 4800 & 2650 & 1200 \\
\hline Thermal conductivity, $\mathrm{W} /(\mathrm{m} \cdot \mathrm{K})$ & 16.2 & 9.7 & 147 & 66.6 \\
\hline Specific heat capacity, J/(kg.K) & 530 & 318 & 739 & 335 \\
\hline Electrical resistivity, $10^{-8} \Omega \cdot \mathrm{m}$ & 74 & 123 & 7.8 & 17.2 \\
\hline
\end{tabular}


(a)

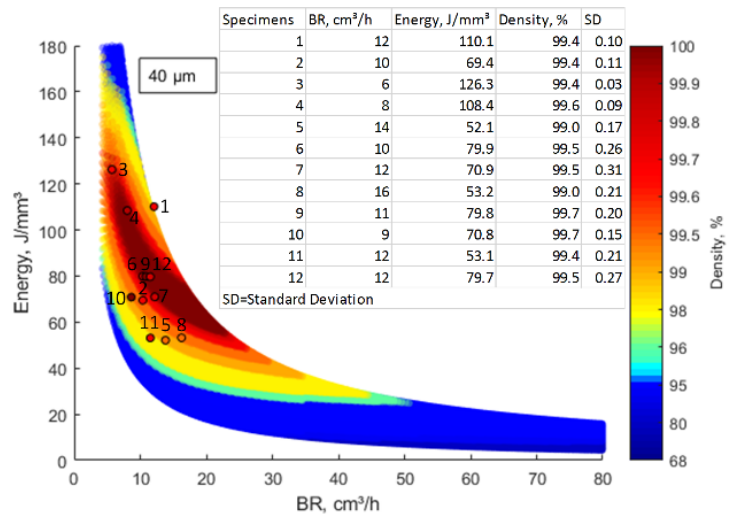

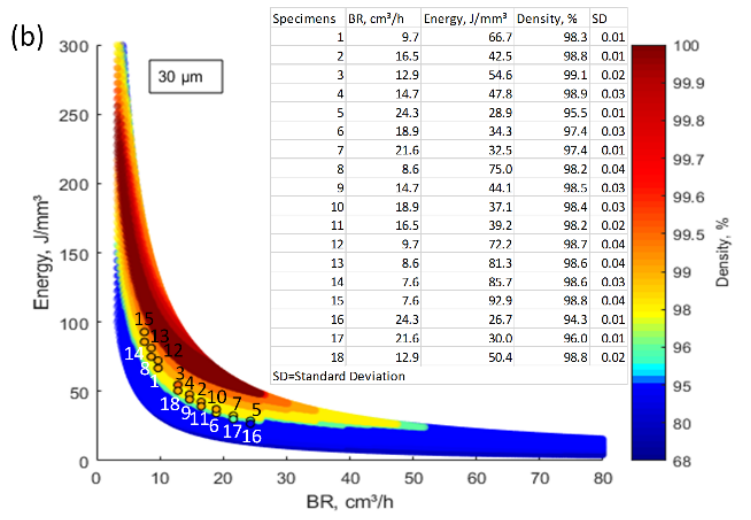

Figure 7. Processing maps for (a) Fe and (b) AlSi10Mg.

\section{Discussion and Application Example}

Notwithstanding that the simplified analytical model used in this study does not take into account the specificities of a given printing system in terms of heat exchange and powder spreading conditions, which both influence the density of the manufactured parts, it was demonstrated that such a model could provide useful information in terms of the energy density and the build rate values, which are potentially suitable for the printing of dense parts. However, to determine the exact set of processing parameters, such as the laser power, speed, hatching space, and layer thickness, an additional condition must be respected, and this condition corresponds to the ratio between the hatching space and the layer thickness, $h / t$.

To establish such a condition, the previously developed model was used to plot the density of IN625 components as a function of the $h / t$ ratio for different layer thicknesses (Figure 8a). From this plot, it is clear that to maximize the material density, the selection of a hatching space must be related to the selection of a layer thickness (Figure $8 \mathrm{~b}$ ). For example, to guarantee the maximum material density $\geq 99.8 \%$, with a layer thickness of $t=30 \mu \mathrm{m}$, the hatching space variations must be limited to the 50 to $80 \mu \mathrm{m}$ range, while for a layer thickness of $t=90 \mu \mathrm{m}$, the hatching space variations must be limited to the 110 to $220 \mu \mathrm{m}$ range.

These results are shown in Figure $8 \mathrm{~b}$ to present the $h-t$ area corresponding to the maximum density of IN625 parts. In the same figure, corresponding $h-t$ areas are plotted for AlSi10Mg (Table 3 ) and Ti64 (Table 4) alloys, for comparison. Finally, once obtained, such plots provide guidance for the selection of the most appropriate hatching space/layer thickness combinations.

(a)

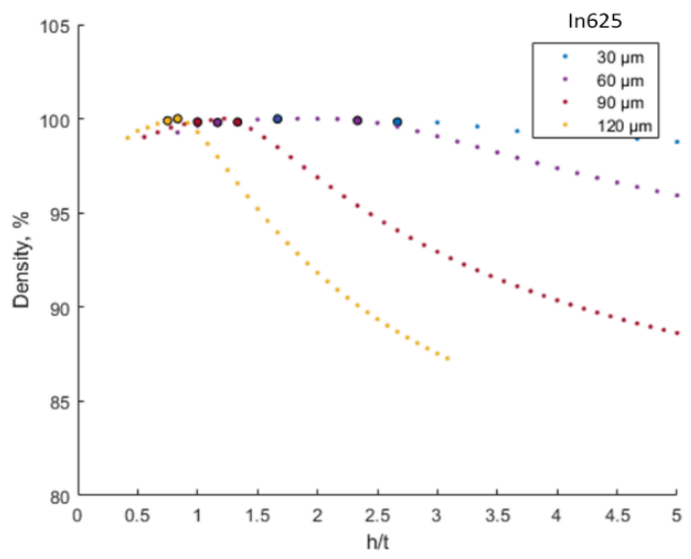

(b)

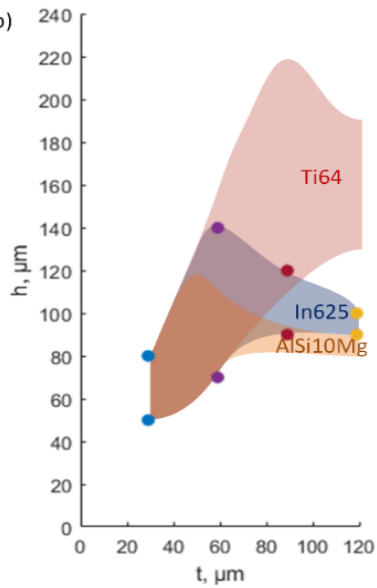

Figure 8. Hatching space/Layer thickness relations: (a) density as a function of the $h / t$ ratio; (b) hatching space as a function of the layer thickness for maximum density $\geq 99.5 \%$ (IN625, AlSi10Mg and Ti64 powders for an EOS M280 LPBF system). 
Note that even though this combined modeling-experiment approach was validated for only one specific LPBF system (EOS M 280), we hypothesize that it can be extended to any LPBF system, provided an adequate calibration experiment is carried out. To this end, after generating the first processing map assuming the physical properties of the material taken from the literature and a powder bed density of $60 \%$, a series of calibration coupons must be printed. Once the density of the printed coupons is measured, the model must be adjusted to fit the experimentally obtained values, by modifying the coefficients of Equation 6. Finally, the relation between the hatching space and the layer thickness can be plotted for a maximum printed material density (see Figure 8b). Once all these conditions are met, the LPBF processing parameters (laser powder, scanning speed, hatching space and layer thickness) can be determined using the following protocol:

1. The layer thickness is selected first to provide a required precision/performance relationship (Figure 9a). If we take $t=40 \mu \mathrm{m}$ to favor precision, the processing map for this layer thickness can be built as shown in Figure 9c.

2. As, in this case, $h$ can vary from 50 to $110 \mu \mathrm{m}$ (Figure $9 \mathrm{~b}$ ), the highest hatch value of $110 \mu \mathrm{m}$ can be specified to improve the process productivity.

3. To print components with a material density $\geq 99.8 \%$ and a maximum allowable build rate of $B R=15 \mathrm{~cm}^{3} / \mathrm{h}$ (Figure 9), the corresponding volumetric laser energy density corresponds to $E=67 \mathrm{~J} / \mathrm{mm}^{3}$ (see the dot in Figure $9 \mathrm{c}$ ). Since $t=40 \mu \mathrm{m}$ and $h=110 \mu \mathrm{m}$, the remaining LPBF parameters can easily be defined using the energy density and build rate definitions of Equations (7) and (8): laser power $\sim 285 \mathrm{~W}$ and scanning speed $\sim 960 \mathrm{~mm} / \mathrm{s}$ [36].

(a)

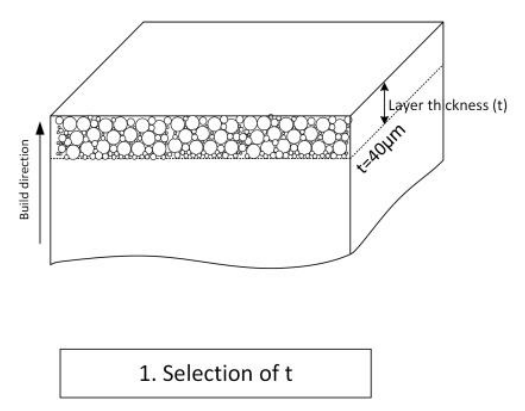

(b)

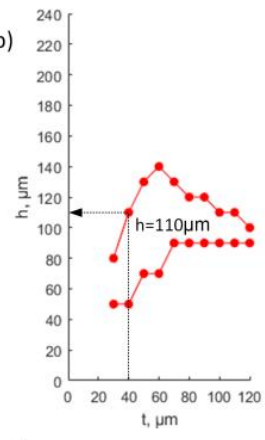

2. Determination of $h$

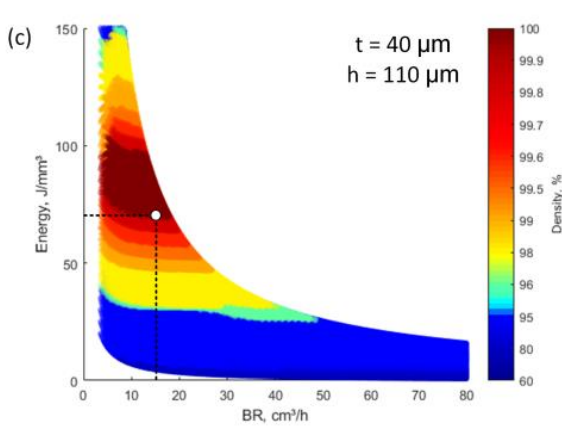

3. Simulation and determination of $P$ and $v$

Figure 9. Steps needed for the printing parameters determination from a processing map: (a) selection of a layer thickness, (b) selection of an appropriate hatching space, and (c) determination of the corresponding laser power and scanning speed values.

As it is widely assumed that the smaller the layer thickness, the better the surface finish and part precision, but the lower the build rate, it is recommended to work with layer thicknesses of 30 or $40 \mu \mathrm{m}$ when precision is required, and of 50 or $60 \mu \mathrm{m}$, when process productivity is more important.

\section{Conclusions}

A simplified analytical model of the LPBF process was used to develop the density prediction algorithm for a given powder feedstock and a given LPBF system. Using a set of density calibration coupons built with the laser power varying from 160 to $350 \mathrm{~W}$; the scanning speed, from 500 to $2800 \mathrm{~mm} / \mathrm{s}$; the hatching space, from 30 to $550 \mu \mathrm{m}$, and the layer thickness, from 30 to $60 \mu \mathrm{m}$, this model was adapted for the IN625 alloy powder and an M280 EOS LPBF system. This approach was then validated for different alloys and processing conditions using literature data, thus demonstrating its potential for the LPBF process optimization. It was also shown that the layer thickness value has a direct influence on the creation of the processing map and must be taken into account during the calibration 
step. This step represents a must-follow requirement to improve the prediction capability of the model because it takes into account the specificities of a given LPBF system related to particular powder recoating and heat transfer conditions, which differ from one printer to another, and influence the final density of the manufactured parts. However, once calibrated for a selected LPBF system, the model could be used for different alloys processed with this same system, avoiding trial-and-error-based process optimization routines.

To further this work, a comprehensive study should be conducted to evaluate the influence of parts' geometry, size, orientation and support on the density predictions.

Author Contributions: The work plan was developed by M.L. to meet the study objectives defined by himself and V.B. The specimen design and the alloy selection were carried out by all the coauthors based upon the state of the art, previous research of V.B., and the current trends in the field. The design, fabrication and testing of the specimens were performed by M.L., V.B. contributed to the data organization, results interpretation and manuscript redaction.

Funding: This research received no external funding.

Acknowledgments: The authors would like to express their appreciation for the financial support provided by NSERC (Natural Sciences and Engineering Research Council of Canada) and for the technical support provided by M. Samoilenko.

Conflicts of Interest: The authors declare no conflict of interest.

\section{Appendix A}

Table A1. Printing parameters, melt pool geometry and density of IN625 test coupons (M280 EOS).

\begin{tabular}{|c|c|c|c|c|c|c|c|c|c|c|}
\hline \multirow{2}{*}{ Spec. } & \multirow{2}{*}{$\begin{array}{c}\text { Power, } \\
\text { W }\end{array}$} & \multirow{2}{*}{$\begin{array}{c}\text { Speed, } \\
\mathrm{m} / \mathrm{s}\end{array}$} & \multirow{2}{*}{$\begin{array}{l}\text { Hatching } \\
\text { space, } \mathrm{mm}\end{array}$} & \multirow{2}{*}{$\begin{array}{c}\text { Energy density, } \\
\mathrm{J} / \mathrm{mm}^{3}\end{array}$} & \multirow{2}{*}{$\begin{array}{c}\text { Build rate, } \\
\mathrm{cm}^{3} / \mathrm{h}\end{array}$} & \multicolumn{3}{|c|}{ Mel pool geometry } & \multirow{2}{*}{$\begin{array}{c}\text { Density, } \\
\%\end{array}$} & \multirow{2}{*}{$\begin{array}{l}\text { SD } \\
\pm \%\end{array}$} \\
\hline & & & & & & $D / t$ & W/h & $L / W$ & & \\
\hline 1 & 160 & 2.8 & 0.092 & 15.6 & 37.0 & 1 & 1 & 5.7 & 78.3 & 0.7 \\
\hline 2 & 160 & 2.8 & 0.061 & 23.3 & 24.7 & 1 & 1.5 & 5.7 & 87.6 & 0.2 \\
\hline 3 & 160 & 2.8 & 0.052 & 27.4 & 21.0 & 1 & 1.76 & 5.7 & 91.6 & 0.3 \\
\hline 4 & 160 & 2.8 & 0.046 & 31.1 & 18.5 & 1 & 2 & 5.7 & 95.6 & 0.1 \\
\hline 5 & 160 & 2.8 & 0.037 & 38.9 & 14.8 & 1 & 2.5 & 5.7 & 95.6 & 0.1 \\
\hline 6 & 160 & 2.8 & 0.031 & 46.7 & 12.3 & 1 & 3 & 5.7 & 97.7 & 0.1 \\
\hline 7 & 225 & 1.94 & 0.265 & 10.9 & 74.1 & 1.5 & 0.5 & 5.7 & 79.03 & 1.1 \\
\hline 8 & 225 & 1.94 & 0.133 & 21.9 & 37.1 & 1.5 & 1 & 5.7 & 92.5 & 0.2 \\
\hline 9 & 225 & 1.94 & 0.088 & 32.8 & 24.7 & 1.5 & 1.5 & 5.7 & 97.3 & 0.1 \\
\hline 10 & 225 & 1.94 & 0.075 & 38.5 & 21.1 & 1.5 & 1.76 & 5.7 & 98.7 & 0.1 \\
\hline 11 & 225 & 1.94 & 0.066 & 43.7 & 18.5 & 1.5 & 2 & 5.7 & 99.5 & 0.1 \\
\hline 12 & 225 & 1.94 & 0.053 & 54.6 & 14.8 & 1.5 & 2.5 & 5.7 & 99.6 & $<0.1$ \\
\hline 13 & 225 & 1.94 & 0.044 & 65.6 & 12.4 & 1.5 & 3 & 5.7 & 99.6 & $<0.1$ \\
\hline 14 & 350 & 1.68 & 0.347 & 15.0 & 83.9 & 2 & 0.5 & 5.4 & 85.0 & 0.3 \\
\hline 15 & 350 & 1.68 & 0.173 & 30.0 & 42.0 & 2 & 1 & 5.4 & 96.4 & 0.1 \\
\hline 16 & 350 & 1.68 & 0.116 & 45.0 & 28.0 & 2 & 1.5 & 5.4 & 99.1 & $<0.1$ \\
\hline 17 & 350 & 1.68 & 0.099 & 52.8 & 23.8 & 2 & 1.76 & 5.4 & 99.4 & $<0.1$ \\
\hline 18 & 350 & 1.68 & 0.087 & 60.0 & 21.0 & 2 & 2 & 5.4 & 99.6 & $<0.1$ \\
\hline 19 & 350 & 1.68 & 0.069 & 75.1 & 16.8 & 2 & 2.5 & 5.4 & 99.4 & 0.1 \\
\hline 20 & 350 & 1.68 & 0.058 & 90.1 & 14.0 & 2 & 3 & 5.4 & 99.6 & 0.1 \\
\hline 21 & 350 & 1.18 & 0.388 & 19.1 & 65.9 & 2.45 & 0.5 & 5.0 & 93.0 & 0.6 \\
\hline 22 & 350 & 1.18 & 0.194 & 38.2 & 32.9 & 2.45 & 1 & 5.0 & 98.9 & 0.1 \\
\hline 23 & 350 & 1.18 & 0.129 & 57.4 & 22.0 & 2.45 & 1.5 & 5.0 & 99.3 & $<0.1$ \\
\hline 24 & 350 & 1.18 & 0.110 & 67.3 & 18.7 & 2.45 & 1.76 & 5.0 & 99.5 & 0.1 \\
\hline 25 & 350 & 1.18 & 0.097 & 76.5 & 16.5 & 2.45 & 2 & 5.0 & 99.4 & 0.1 \\
\hline 26 & 350 & 1.18 & 0.078 & 95.6 & 13.2 & 2.45 & 2.5 & 5.0 & 99.6 & 0.1 \\
\hline 27 & 350 & 1.18 & 0.065 & 114.7 & 11.0 & 2.45 & 3 & 5.0 & 99.7 & 0.2 \\
\hline 28 & 345 & 1.06 & 0.429 & 19.0 & 65.4 & 2.5 & 0.5 & 4.5 & 93.3 & 0.1 \\
\hline 29 & 345 & 1.06 & 0.214 & 38.0 & 32.7 & 2.5 & 1 & 4.5 & 98.7 & 0.2 \\
\hline 30 & 345 & 1.06 & 0.143 & 57.0 & 21.8 & 2.5 & 1.5 & 4.5 & 99.3 & 0.2 \\
\hline 31 & 345 & 1.06 & 0.122 & 66.8 & 18.6 & 2.5 & 1.76 & 4.5 & 99.4 & 0.1 \\
\hline 32 & 345 & 1.06 & 0.107 & 75.9 & 16.4 & 2.5 & 2 & 4.5 & 99.4 & $<0.1$ \\
\hline 33 & 345 & 1.06 & 0.086 & 94.9 & 13.1 & 2.5 & 2.5 & 4.5 & 99.5 & $<0.1$ \\
\hline 34 & 345 & 1.06 & 0.071 & 113.9 & 10.9 & 2.5 & 3 & 4.5 & 99.7 & 0.1 \\
\hline 35 & 350 & 0.8 & 0.469 & 23.3 & 54.1 & 3 & 0.5 & 3.9 & 94.3 & 0.1 \\
\hline 36 & 350 & 0.8 & 0.235 & 46.6 & 27.0 & 3 & 1 & 3.9 & 99.1 & 0.1 \\
\hline 37 & 350 & 0.8 & 0.156 & 69.9 & 18.0 & 3 & 1.5 & 3.9 & 99.5 & $<0.1$ \\
\hline 38 & 350 & 0.8 & 0.133 & 82.0 & 15.4 & 3 & 1.76 & 3.9 & 99.5 & 0.1 \\
\hline
\end{tabular}


Table A1. Cont.

\begin{tabular}{|c|c|c|c|c|c|c|c|c|c|c|}
\hline \multirow{2}{*}{ Spec. } & \multirow{2}{*}{$\begin{array}{c}\text { Power, } \\
\text { W }\end{array}$} & \multirow{2}{*}{$\begin{array}{c}\text { Speed, } \\
\mathrm{m} / \mathrm{s}\end{array}$} & \multirow{2}{*}{$\begin{array}{l}\text { Hatching } \\
\text { space, } \mathrm{mm}\end{array}$} & \multirow{2}{*}{$\begin{array}{l}\text { Energy density, } \\
\mathrm{J} / \mathrm{mm}^{3}\end{array}$} & \multirow{2}{*}{$\begin{array}{c}\text { Build rate, } \\
\mathrm{cm}^{3} / \mathrm{h}\end{array}$} & \multicolumn{3}{|c|}{ Mel pool geometry } & \multirow{2}{*}{$\begin{array}{c}\text { Density, } \\
\%\end{array}$} & \multirow{2}{*}{$\begin{array}{l}\text { SD } \\
\pm \%\end{array}$} \\
\hline & & & & & & $D / t$ & W/h & $L / W$ & & \\
\hline 39 & 350 & 0.8 & 0.117 & 93.2 & 13.5 & 3 & 2 & 3.9 & 99.7 & 0.1 \\
\hline 40 & 350 & 0.8 & 0.094 & 116.5 & 10.8 & 3 & 2.5 & 3.9 & 99.4 & 0.1 \\
\hline 41 & 340 & 0.56 & 0.551 & 27.5 & 44.4 & 3.5 & 0.5 & 3.4 & 96.3 & 0.1 \\
\hline 42 & 340 & 0.56 & 0.276 & 55.1 & 22.2 & 3.5 & 1 & 3.4 & 99.4 & 0.1 \\
\hline 43 & 340 & 0.56 & 0.184 & 82.6 & 14.8 & 3.5 & 1.5 & 3.4 & 99.4 & 0.2 \\
\hline 44 & 340 & 0.56 & 0.157 & 97.0 & 12.6 & 3.5 & 1.76 & 3.4 & 99.5 & 0.1 \\
\hline 45 & 340 & 0.56 & 0.138 & 110.2 & 11.1 & 3.5 & 2 & 3.4 & 99.2 & 0.2 \\
\hline
\end{tabular}

\section{References}

1. Huang, Y.; Leu, M.C.; Mazumder, J.; Donmez, A. Additive manufacturing: Current state, future potential, gaps and needs, and recommendations. J. Manuf. Sci. Eng. 2015, 137, 014001. [CrossRef]

2. Brandt, M. Laser Additive Manufacturing: Materials, Design, Technologies, and Applications; Woodhead Publishing: Cambridge, UK, 2016.

3. Kasperovich, G.; Haubrich, J.; Gussone, J.; Requena, G. Correlation between porosity and processing parameters in TiAl6V4 produced by selective laser melting. Mater. Des. 2016, 105, 160-170. [CrossRef]

4. Delgado, J.; Ciurana, J.; Rodríguez, C.A. Influence of process parameters on part quality and mechanical properties for DMLS and SLM with iron-based materials. Int. J. Adv. Manuf. Technol. 2012, 60, 601-610. [CrossRef]

5. Kurzynowski, T.; Chlebus, E.; Kuźnicka, B.; Reiner, J. Parameters in Selective Laser Melting for processing metallic powders. In Proceedings of the High Power Laser Materials Processing: Lasers, Beam Delivery, Diagnostics, and Applications, San Francisco, CA, USA, 24-26 January 2012; Volume 8239.

6. Bartolomeu, F.; Faria, S.; Carvalho, O.; Pinto, E.; Alves, N.; Silva, F.S.; Miranda, G. Predictive models for physical and mechanical properties of Ti6Al4V produced by Selective Laser Melting. Mater. Sci. Eng. A 2016, 663, 181-192. [CrossRef]

7. Ahmed, A.; Wahab, M.S.; Raus, A.A.; Kamarudin, K.; Bakhsh, Q.; Ali, D. Effects of Selective Laser Melting Parameters on Relative Density of AlSi10Mg. Int. J. Eng. Technol. 2016, 8, 2552-2557. [CrossRef]

8. Cherry, J.A.; Davies, H.M.; Mehmood, S.; Lavery, N.P.; Brown, S.G.; Sienz, J. Investigation into the Effect of process parameters on microstructural and physical properties of 316L stainless steel parts by selective laser melting. Int. J. Adv. Manuf. Technol. 2014, 76, 869-879. [CrossRef]

9. Rashid, R.; Masood, S.H.; Ruan, D.; Palanisamy, S.; Rahman Rashid, R.A.; Elambasseril, J.; Brandt, M. Effect of energy per layer on the anisotropy of selective laser melted AlSi12 aluminium alloy. Addit. Manuf. 2018, 22, 426-439. [CrossRef]

10. Rashid, R.; Masood, S.H.; Ruan, D.; Palanisamy, S.; Rashid, R.R.; Brandt, M. Effect of scan strategy on density and metallurgical properties of 17-4PH parts printed by Selective Laser Melting (SLM). J. Mater. Process. Technol. 2017, 249, 502-511. [CrossRef]

11. Foroozmehr, A.; Badrossamay, M.; Foroozmehr, E. Finite element simulation of selective laser melting process considering optical penetration depth of laser in powder bed. Mater. Des. 2016, 89, 255-263. [CrossRef]

12. Fischer, P.; Karapatis, N.; Romano, V.; Glardon, R.; Weber, H.P. A model for the interaction of near-infrared laser pulses with metal powders in selective laser sintering. Appl. Phys. A 2002, 74, 467-474. [CrossRef]

13. Fischer, P.; Romano, V.; Weber, H.P.; Karapatis, N.P.; Boillat, E.; Glardon, R. Sintering of commercially pure titanium powder with a Nd: YAG laser source. Acta Mater. 2003, 51, 1651-1662. [CrossRef]

14. Li, Y.; Gu, D. Parametric analysis of thermal behavior during selective laser melting additive manufacturing of aluminum alloy powder. Mater. Des. 2014, 63, 856-867. [CrossRef]

15. Zhang, Z.; Huang, Y.; Kasinathan, A.R.; Shahabad, S.I.; Ali, U.; Mahmoodkhani, Y.; Toyserkani, E. 3-Dimensional heat transfer modeling for laser powder-bed fusion additive manufacturing with volumetric heat sources based on varied thermal conductivity and absorptivity. Opt. Laser Technol. 2019, 109, 297-312. [CrossRef]

16. Yadroitsev, I.; Yadroitsava, I.; Bertrand, P.; Smurov, I. Philippe Bertrand and Igor Smurov, Factor analysis of selective laser melting process parameters and geometrical characteristics of synthesized single tracks. Rapid Prototyp. J. 2012, 18, 201-208. [CrossRef] 
17. Aboulkhair, N.T.; Everitt, N.M.; Ashcroft, I.; Tuck, C. Reducing porosity in AlSi10Mg parts processed by selective laser melting. Addit. Manuf. 2014, 1,77-86. [CrossRef]

18. Letenneur, M.; Brailovski, V.; Kreitcberg, A.; Paserin, V.; Bailon-Poujol, I. Laser powder bed fusion of water-atomized iron-based powders: Process optimization. J. Manuf. Mater. Process. 2017, 1, 23. [CrossRef]

19. Schuöcker, D. Handbook of the Eurolaser Academy; Springer Science \& Business Media: Vienna, Austria, 1998; Volume 2.

20. Kreitcberg, A.; Brailovski, V.; Prokoshkin, S. New biocompatible near-beta Ti-Zr-Nb alloy processed by laser powder bed fusion: Process optimization. J. Mater. Process. Technol. 2018, 252, 821-829. [CrossRef]

21. Hagen, E.; Rubens, H. Über Beziehungen des Reflexions-und Emissionsvermögens der Metalle zu ihrem elektrischen Leitvermögen. Ann. Phys. 1903, 316, 873-901. [CrossRef]

22. Bala, K.; Pradhan, P.R.; Saxena, N.S.; Saksena, M.P. Effective thermal conductivity of copper powders. J. Phys. D Appl. Phys. 1989, 22, 1068. [CrossRef]

23. Sumirat, I.; Ando, Y.; Shimamura, S. Theoretical consideration of the effect of porosity on thermal conductivity of porous materials. J. Porous Mater. 2006, 13, 439-443. [CrossRef]

24. Liu, P.; Fu, C.; Li, T. Calculation formula for apparent electrical resistivity of high porosity metal materials. Sci. China Ser. E Technol. Sci. 1999, 42, 294-301. [CrossRef]

25. Jacob, G.; Donmez, A.; Slotwinski, J.; Moylan, S. Measurement of powder bed density in powder bed fusion additive manufacturing processes. Meas. Sci. Technol. 2016, 27, 115601. [CrossRef]

26. American Society for Metals. Metals Handbook. 2. Properties and Selection: Nonferrous Alloys and Special-Purpose Materials; American Society for Metals: Materials Park, OH, USA, 1990.

27. Davis, J.R. ASM Specialty Handbook: Heat-Resistant Materials; ASM International: Materials Park, OH, USA, 1997.

28. Gunenthiram, V.; Peyre, P.; Schneider, M.; Dal, M.; Coste, F.; Fabbro, R. Analysis of laser-melt pool-powder bed interaction during the selective laser melting of a stainless steel. J. Laser Appl. 2017, 29, 022303. [CrossRef]

29. King, W.E.; Anderson, A.T.; Ferencz, R.M.; Hodge, N.E.; Kamath, C.; Khairallah, S.A.; Rubenchik, A.M. Laser powder bed fusion additive manufacturing of metals; physics, computational, and materials challenges. Appl. Phys. Rev. 2015, 2, 041304. [CrossRef]

30. Silbernagel, C.; Ashcroft, I.; Dickens, P.; Galea, M. Electrical resistivity of additively manufactured AlSi10Mg for use in electric motors. Addit. Manuf. 2018, 21, 395-403. [CrossRef]

31. Abd-Elghany, K.; Bourell, D. Property evaluation of 304L stainless steel fabricated by selective laser melting. Rapid Prototyp. J. 2012, 18, 420-428. [CrossRef]

32. Spierings, A.B.; Levy, G. Comparison of density of stainless steel 316L parts produced with selective laser melting using different powder grades. In Proceedings of the Annual International Solid Freeform Fabrication Symposium, Austin, TX, USA, 3-5 August 2009.

33. Jacob, G.; Brown, C.U.; Donmez, M.A. The Influence of Spreading Metal Powders with Different Particle Size Distributions on the Powder Bed Density in Laser-Based Powder Bed Fusion Processes; Advanced Manufacturing Series (NIST AMS) 100-17; National Institute of Standards and Technology (NIST): Gaithersburg, MD, USA, 2018.

34. Polmear, I.J. Light Alloys: From Traditional Alloys to Nanocrystals, 4th ed.; Elsevier: Oxford, UK, 2005.

35. Krishnan, M.; Atzeni, E.; Canali, R.; Calignano, F.; Manfredi, D.; Ambrosio, E.P.; Iuliano, L. On the effect of process parameters on properties of AlSi10Mg parts produced by DMLS. Rapid Prototyp. J. 2014, 20, 449-458. [CrossRef]

36. Poulin, J.-R.; Letenneur, M.; Terriault, P.; Brailovski, V. Influence of intentionally-induced porosity and post-processing conditions on the mechanical properties of laser powder bed fused inconel 625. In Selected Technical Papers (STP1620), Proceedings of ASTM Symposium on Structural Integrity of Additive Manufactured Parts, Washington, DC, USA, 6-8 November 2018; ASTM International: West Conshohocken, PA, USA, 2018.

(C) 2019 by the authors. Licensee MDPI, Basel, Switzerland. This article is an open access article distributed under the terms and conditions of the Creative Commons Attribution (CC BY) license (http://creativecommons.org/licenses/by/4.0/). 